\title{
Generation of Optimal Switching Angle for Nine Level Cascaded H Bridge MLI Using Most Valuable Player Algorithm
}

\author{
Vijaya Anand N a, Hema Latha J b ,G Devadasu ${ }^{c}$, Kumar $C^{d}$ \\ a Associate Professor, Department of EEE, PVP Siddhartha Institute of Technology, Kanuru, Vijayawada, Andhra Pradesh \\ ${ }^{\mathrm{b}}$ Sr.Assistant professor, Department of EEE, PVP Siddhartha Institute of Technology, Kanuru, Vijayawada, Andhra Pradesh \\ ${ }^{c}$ Professor, Department of EEE, CMR College of Engineering \&Technology, Medchal, Hyderabad, Telangana \\ d Associate Professor, Department of EEE, PVP Siddhartha Institute of Technology, Kanuru, Vijayawada, Andhra Pradesh \\ anidumoluvijay@gmail.com
}

Article History: Received: 10 November 2020; Revised 12 January 2021 Accepted: 27 January 2021; Published online: 5 April 2021

\begin{abstract}
Distributed generation (DG) sources often interfaced with grid by a Cascaded H-bridge multilevel inverter with a remote D.C source. The interface inverter has to adapt voltage on the either side of the grid and DG source while it has a control of active and reactive power exchange. The inverter terminal voltage is maintained based on frequency switching technique. However, in applications like micro grids are based on quality of output voltage at the point of common coupling. The present paper discusses an optimal frequency switching methodology that generates optimal fringing angle based on an evolutionary computing technique while maintaining the voltage level at PCC with a reduced harmonic distortion. Efficacy of the proposed method is illustrated by simulating a 9-level cascaded $\mathrm{H}$ bridge in MATLAB environment.
\end{abstract}

Keywords: Multi Level Inverter, Cascaded H Bridge, Particle Swarm Optimization, Most Valuable player Algorithm, Switching Angle Minimization

\section{Introduction}

Many of the high-power applications are developed based on Multi Level Inverters (MLI). MLI can synthesize near sinusoidal voltage [1] by selecting suitable number DC voltage sources.Different MLI topologieswere developed based on input supply that can be either a battery or an isolated source like PV, fuel cell [2-7]. Cascaded H-bridge (CHB) converters [8--10] in particular gained attention of many researchers in facilitating high and medium power application with an appropriate modulation technique towards an efficient switching control.

Sinusoidal Pulse Width Modulation (SPWM)and Selective Harmonic Elimination (SHE) [11] are the control techniques that generates output voltage with a reduced harmonic distortion. In SHE the number of pulses per half cycle are likely to less than SPWM resulting in lower switching losses. This feature is very much helpful in switching a solid-state device in high power application due to low switching loss.

In SHE [12] technique the switching angles derived are based on unconstrained equations that characterizes the harmonics. Theses equations are highly nonlinear and quite difficult to get exact solution for a chosen value of modulation index. Solution for this method is derived base on numerical iterative techniques with proper initial guess. In [13-18] proposed the solution for the SHE technique using the soft computing approaches to have fewer harmonic levels at the output.

Many researchers consider fundamental frequency switching method as an alternative to SHE technique as it generates better output voltage wave form and a fundamental component. However, voltage at Point of Common Coupling (PCC) is the main concern in a grid connected systems rather than the inverter output voltage.

SHEPWM switching method proposed for the grid connected multilevel inverters is based on injecting the specific harmonic by one inverter and absorbing the same by another inverter so that specific harmonics are eliminated at PCC in view of voltage quality. This method may result in reduced line voltage, THD at PCC but does not meet the standard limit of grid code.

This paper presents an enhanced fundamental frequency switching based harmonic mitigation for a grid connected cascaded MLI. The main motto is to determine the optimum switching angles for a MLI so that it moderates the THD, individual harmonic components of voltage waveform at PCC in accord with the standard. 


\section{Cascaded Multilevel Inverter}

CHBMLI are constructed from succession connection of single-phase H-bridge MLI [19] . The CHBMLI construction known to be modular because of their circuit, control and modulation technique adopted. The modular structure enables CHBMLI [20-21] to operate reliably at higher power level, voltage and less maintenance compared with the other MLI techniques that are commonly adopted such as diode clamped and flying capacitor MLI's. In CHBMLI number of DC link voltages (P) or switching angles governs the associated levels with the output voltage waveform that are given by $2 \mathrm{P}+1$. Fig. 1a shows CHBMLI that generates a 9-level output With, $\mathrm{P}=4$. Each switch in an $\mathrm{H}$-bridge alters its state twice over a cycle period. Fig $1 \mathrm{~b}$ depicts the phase output voltage of a 9 level CHBMLI with each $\mathrm{H}$ bridge altering its state twice over a cycle.

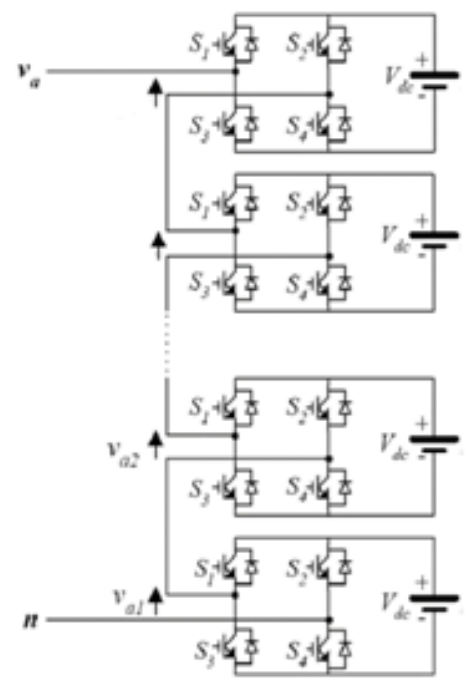

(a)

(b)

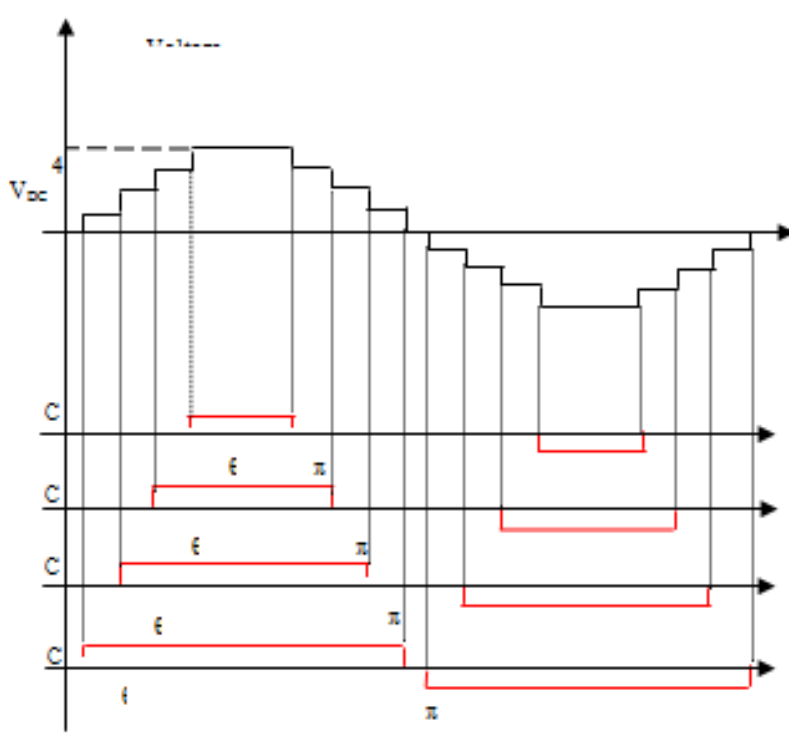

Fig.1. (a) Structure of a 9-Level CHBMLI. $\quad$ (b) Output voltage

Each DC link is connected to a single phase full-bridge inverter and can generate three different voltage outputs, $+\mathrm{Vdc}, 0$ and $-\mathrm{Vdc}$. each level's full-bridge inverter is connected in succession such that the synthesized voltage waveform is the sum of all of the individual outputs.

\subsection{Selective Harmonics Elimination}

A 9- level output voltage from CHBMLI for a single phase as shown in Fig. 1(b) the output voltage waveform that is having quarter-wave symmetric with $\mathrm{P}$ number of steps that are generated from equal magnitudes $\mathrm{V} 1=\mathrm{V} 2$ $=\mathrm{V} 3=\ldots=\mathrm{VDC}$. The fundamental component of the inverter output voltage has particular magnitude and phase angle are represented as $V_{1}$ and $\delta$. Then the Fourier analysis of the inverter output voltage waveform is given by,

$$
V_{\text {inv }}(\omega t)=\sum_{\mathrm{n}}^{\infty}=1,3,5, \ldots . .\left[\frac{4 \mathrm{~V}_{\mathrm{DC}}}{\mathrm{n} \pi} \sum_{n=1}^{S} \cos \left(n \alpha_{k}\right)\right] * \sin (n \omega t+n \delta)
$$

Where $\alpha \mathrm{k}$ is the kth inverter switching angle and $\mathrm{n}$ is the harmonic order.

When the switch angles are zero then the inverter output voltage yields the maximum voltage (V1max) given as $V\left(\frac{4 V_{D C}}{\pi}\right)_{1 \max }$

. The ratio of Fundamental output voltage and maximum output voltage is defined as The modulation $\operatorname{index}(\mathrm{M})$ and is represented as

$$
M=\frac{V_{1}}{3 *\left(\frac{4 V_{D C}}{\pi}\right)}
$$

For the 9-level CHBMLI the set of nonlinear equations that helps in mitigating the lower order harmonics like 3rd ,5th and 7th in achieving the desired output voltage at distinct values of $\mathrm{M}$ (from 0 to 1 ) are given by

$$
\begin{gathered}
\cos \left(\theta_{1}\right)+\cos \left(\theta_{2}\right)+\cos \left(\theta_{3}\right)+\cos \left(\theta_{4}\right)=3 M \\
\cos \left(3 \theta_{1}\right)+\cos \left(3 \theta_{2}\right)+\cos \left(3 \theta_{3}\right)+\cos \left(3 \theta_{4}\right)=0
\end{gathered}
$$


$\cos \left(5 \theta_{1}\right)+\cos \left(5 \theta_{2}\right)+\cos \left(5 \theta_{3}\right)+\cos \left(5 \theta_{4}\right)=0$

$\cos \left(7 \theta_{1}\right)+\cos \left(7 \theta_{2}\right)+\cos \left(7 \theta_{3}\right)+\cos \left(7 \theta_{4}\right)=0$

The solutions of equation (4) give the switching angles for the CHBMLI. Solution of equation (4) might not be achievable for certain values of $\mathrm{M}$ in mitigating the targeted harmonics. In order to obtain a feasible solution using SHE technique an objective function is formulated and is represented as

$$
J=\min \left\{\left(100 \frac{V_{1}^{*}-V_{1}}{V_{1}^{*}}\right)^{4}+\sum_{n=3}^{N_{l}-2} \frac{1}{n}\left(50 \frac{V_{n}}{V_{1}}\right)^{2}\right\}
$$

Subject to $0 \leq \theta_{i} \leq \pi / 2$

The objective function is formulated to sustain the error in fundamental from reference lie within $1 \%$ and harmonics are limited to the $2 \%$ of fundamental value to meet the IEEE-519 harmonic standard. $V_{n}$ is given by

$$
V_{n}=\frac{4 V_{D C}}{n \pi} \sum_{i=1}^{N_{D C}} K_{i} \cos \left(n \theta_{i}\right)
$$

$V_{n}$ is the nth harmonic voltage. $\boldsymbol{K}_{\boldsymbol{i}}$ is the ratio of $\left(\frac{V_{D C i}}{V_{D C}}\right)$. Where $\mathrm{i}$ is the no. of D.C voltage sources, $\theta_{i}$ switching angle limited to $90^{\circ}$ and $\mathrm{N}$ dc $=4$.

\section{Most Valuable Player Algorithm (MVPA):}

Optimization of real-world problems can be categorised into convention and heuristic algorithms. The conventional algorithm showed their potential with continuous objective function like gradient method. But, failed to prove with discontinuities in the objective function where meta heuristic algorithm can cope of with such problems. Metaheuristic algorithms are flashed out nature. Few of the algorithm shown their potential like Genetic Algorithm (GA), Differential Evolution (DE), Particle Swarm Optimization (PSO),Firefly Algorithm (FA) Teaching-Learning-Based Optimization (TLBO), Artificial Bee Colony (ABC), and Gray Wolf search algorithm(GWO), become popular.

Most Valuable Player Algorithm (MVPA) is stochastic optimisation algorithm invented by H. R. E. H. Bouchekara [23]. Players having proficiencies are e considered as population, where proficiencies correspond to dimensions of the problem. The competence of a player or a team corresponds to fitness. Each team consist of finest player and the tournament valuable player is finest player of league.

The proposed (MVPA) comprises of the following steps (i) Initialization and formation of team where the players initialised randomly and teams are formulated randomly (ii) Competition phase : In this phase, players try to progress their proficiencies individually by playing in the matches with the other teams and try to emerge as most valuable player in the team as well as tournament. (iii) Termination phase: when the algorithm runs for maximum number of iterations it terminates 


\subsection{Algorithm To Calculate Switching Angles}

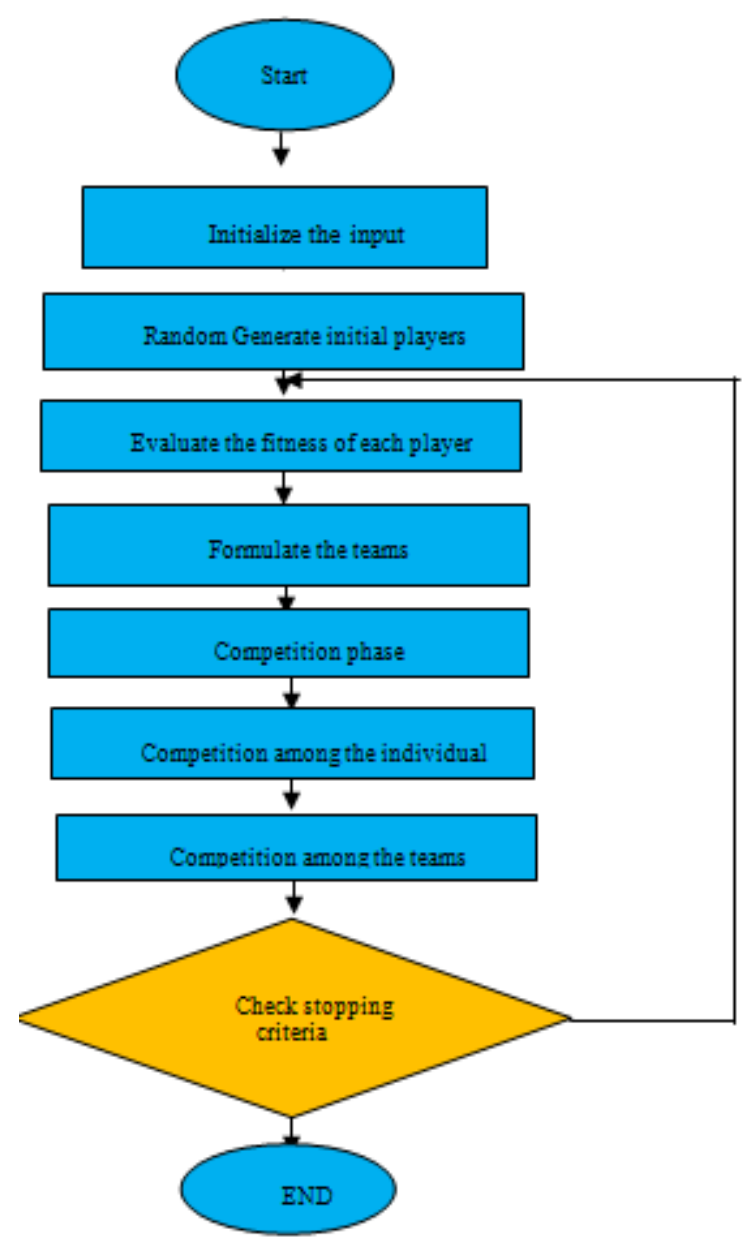

Fig.2. Flowchart to calculate the switching angles

Step1: The algorithm started with initialization of the players ( 4 switching angles) for the 4S-9L MLI randomly. For example, with 20 player and 5 teams each team have 4 players.

Step2: The objective function $J$ is evaluated for each set of switching angles with the subjected constraint for each value of $\mathrm{M}$.

Step3: Teams are formulated randomly.

Step4: Completion is held among the team members and proficiencies are update among the player and teams.

Step5: Repeat till the maximum number of iterations. Otherwise, increase the iteration counter and go to step2 for the range of M,i.e.0-1.

\section{Simulation Results}

The sample system employed for 9-level CHBMLI is shown below figure 3. The PWM technique used for switching the devices is selective harmonic elimination technique. The simulation parameters required for the pulse generation are calculated based on the switching angles generated by NR method PSO algorithm and MVP algorithm. The grid parameters and inverter parameters are given in table 1. IGBT switches are triggered according to the switching angles generated by the NR, PSO and MVPA algorithm. 


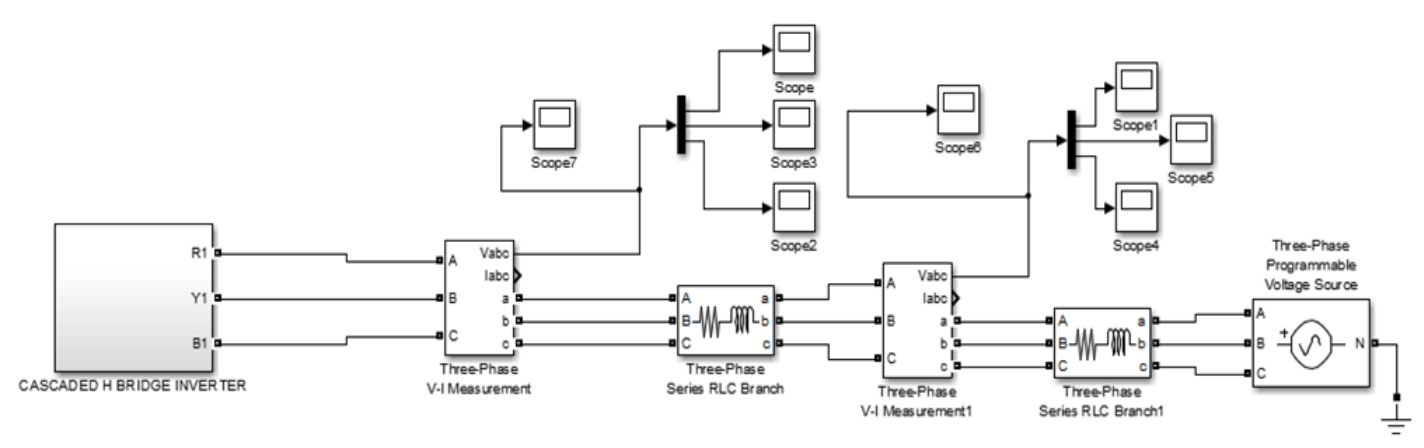

Figure 3 Sample System of Grid Connected Inverter for Switching Methods

Table 1Grid Parameters And Inverter Parameters

\begin{tabular}{|c|c|c|c|}
\hline \multicolumn{2}{|c|}{ Grid parameters } & \multicolumn{2}{|c|}{ Inverter parameters } \\
\hline $\begin{array}{c}\text { RMS of the } \\
\text { phase Voltage }\end{array}$ & $230 \mathrm{~V}$ & $\begin{array}{c}\text { Dc voltage } \\
\text { source }\end{array}$ & $57.5 \mathrm{v}$ \\
\hline $\begin{array}{c}\text { Equivalent } \\
\text { resistance }\end{array}$ & $0.6 \mathrm{ohm}$ & Switch type & IGBT \\
\hline $\begin{array}{c}\text { Equivalent } \\
\text { inductance }\end{array}$ & $0.1 \mathrm{Mh}$ & $\begin{array}{c}\text { Internal } \\
\text { resistance }\end{array}$ & $\begin{array}{c}0.001 \\
\text { ohm }\end{array}$ \\
\hline
\end{tabular}

A MATLAB program-based NR-method is applied to the differential equations with the different values of modulation indices. The initial guess to run simulation MATLAB program are $\alpha_{1}=20^{\circ}, \alpha_{2}=40^{\circ}, \alpha_{3}=60^{\circ}, \alpha_{4}=$ $80^{\circ}$. Whereas the other two methods are based on stochastic optimization initial values are randomly generated. From the switching angles the required simulation parameters like time period, pulse width and the phase delay were calculated to give switching instants for the pulse generator. Table 2 shows the comparative results generated using the three methodsconsidered for the generation of switching angles. PSO algorithm[22] is applied with 4 particles, population size of 50, cognition parameter $\mathrm{c} 1=2$, social parameter $\mathrm{c} 2=4-\mathrm{c} 1, \mathrm{~V}_{\mathrm{dc}}=57.5 \mathrm{~V}$, Vref $=400 \mathrm{~V}$ and maximum number of iterations $=250$. MVP algorithm is implemented with 20 players and 4 teams with maximum number of iterations $=250$.

Table 2 Three Phase Inverter Switching Angles

\begin{tabular}{|c|c|c|c|c|c|c|c|c|c|}
\hline \multirow{2}{*}{ gle $^{\text {An }}$} & \multicolumn{3}{|c|}{ NR Method } & \multicolumn{3}{|c|}{ PSO Algorithm } & \multicolumn{3}{|c|}{ MVP Algorithm } \\
\hline & \multicolumn{3}{|c|}{ R-phase(degrees) } & \multicolumn{3}{|c|}{ Y-phase(degrees) } & \multicolumn{3}{|c|}{ B-phase(degrees) } \\
\hline$\alpha_{1}$ & $59^{0}$ & $8^{0}$ & $8^{0} \begin{array}{l}1.95 \\
\end{array}$ & $59^{0}$ & $58^{0}$ & $58^{0} 121.9$ & $59^{263.5}$ & $58^{0}$ & $58^{0}$ \\
\hline$\alpha_{2}$ & $59^{39.2}$ & $80^{0} 27.2$ & $20^{0} 25.8$ & $59^{0}$ & $80^{0}$ & $20^{0}$ & $59^{0}$ & $80^{0}{ }^{267.2}$ & $20^{0}$ \\
\hline$\alpha_{3}$ & $6^{0}$ & $42^{0}$ & $64^{0}$ & $6^{0} 168.9$ & $42^{0}$ & $64^{0}$ & $6^{0} 288.9$ & $42^{0}$ & $64^{0}$ \\
\hline$\alpha_{4}$ & $24^{0} 89.2$ & $27^{68.3}$ & $17^{63.1}$ & $24^{0}$ & $27^{0}$ & $17^{0}$ & $24^{0} 329.2$ & $27^{0}$ & $17^{0}$ \\
\hline
\end{tabular}

The three-phase inverter is designed from the obtained switching angles with inverter connected in star configuration. The output of three phase inverter is shown in figure 4. With NR method the output voltage between the two lines at fundamental frequency $(50 \mathrm{~Hz})$ is $298.9 \mathrm{~V}$. PSO algorithm resulted in output voltage between the two lines at fundamental frequency $(50 \mathrm{~Hz})$ is $382.4 \mathrm{~V}$ and with the MVP algorithm output voltage between the two lines at fundamental frequency $(50 \mathrm{~Hz})$ is $390.7 \mathrm{~V}$ for a reference voltage of $400 \mathrm{~V}$ between lines. 


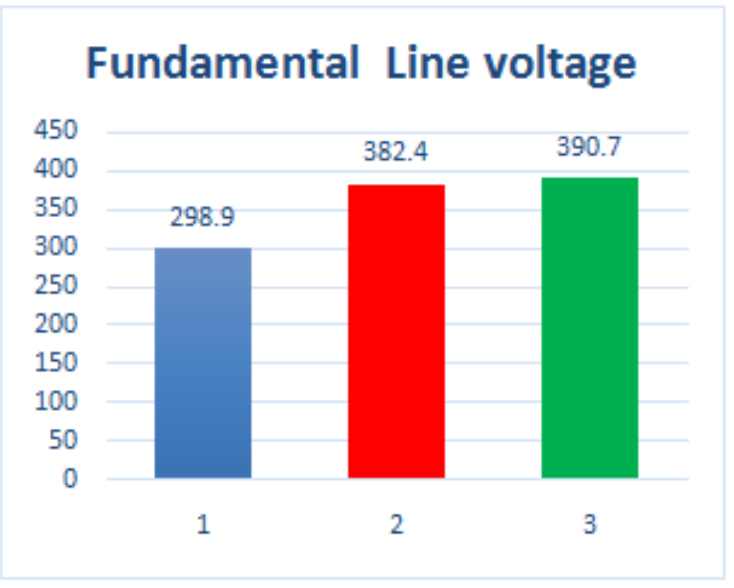

a)Voltage at Line terminal

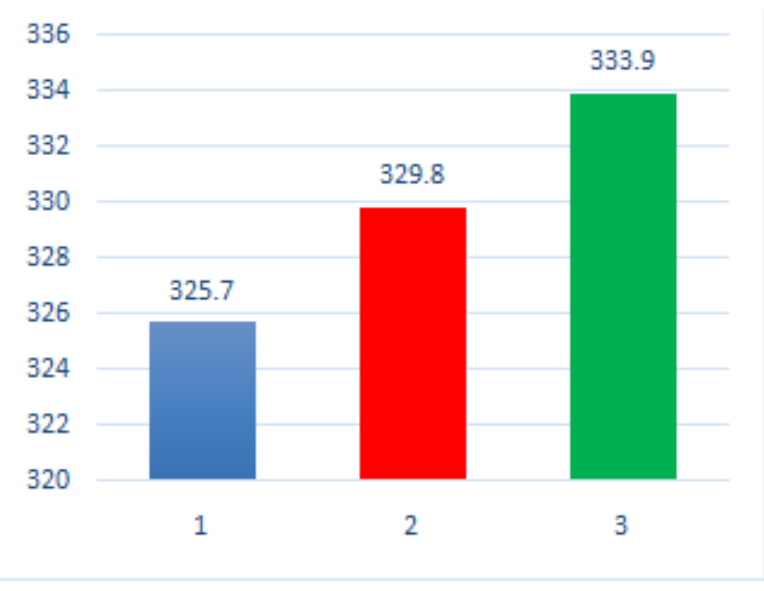

b)Voltage at PCC

Fig. 4. Three Phase Line Voltages

The \% of THD between obtained NR, PSO algorithm and MVP algorithm are compared and tabulated in table 3. Voltage of the three-phase inverter from the MVP algorithm is better compared to NR method and PSO algorithm. FFT analysis the THD values between line to line in three phase inverters is observed to be $17.75 \%$ with NR method, $13.98 \%$ with PSO algorithm and 5.74\%MVP algorithm resulting in lower value. It also observed from the table that with MVP algorithm THD of $12.46 \%$ resulting out of set of optimal switching angles that generates the output voltage with less hormonic and better voltage magnitude when compared with the other existing techniques. Figure 5 give the FFT analysis of 3 phase inverters.

Table 3 Performance Comparison of a Three phase inverter

\begin{tabular}{|l|l|l|l|l|l|l|}
\hline Parameter & \multicolumn{2}{|l|}{ NR Method } & \multicolumn{2}{l|}{ PSO Algorithm } & \multicolumn{2}{l|}{ MVP Algorithm } \\
\cline { 2 - 7 } & $\begin{array}{l}\text { InverterLine } \\
\text { voltage }\end{array}$ & $\begin{array}{l}\text { PCC } \\
\text { line } \\
\text { voltage }\end{array}$ & $\begin{array}{l}\text { InverterLine } \\
\text { voltage }\end{array}$ & $\begin{array}{l}\text { PCC } \\
\text { line } \\
\text { Voltage }\end{array}$ & $\begin{array}{l}\text { InverterLine } \\
\text { voltage }\end{array}$ & $\begin{array}{l}\text { PCC } \\
\text { line } \\
\text { voltage }\end{array}$ \\
\hline $\begin{array}{l}\text { Fundamental } \\
\text { output voltage }\end{array}$ & 298.9 & 325.7 & 329.8 & 382.4 & 333.9 & 390.7 \\
\hline $\begin{array}{l}\text { Rms output } \\
\text { voltage }\end{array}$ & 211.35 & 230.30 & 233.20 & 270.39 & 236.10 & 276.27 \\
\hline THD $\%)$ & 17.75 & 10.33 & 13.98 & 6.95 & 12.46 & 5.74 \\
\hline
\end{tabular}




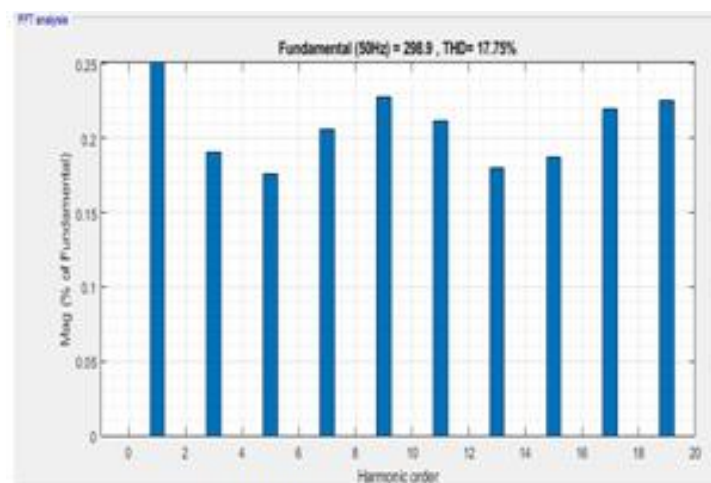

a) NR Method

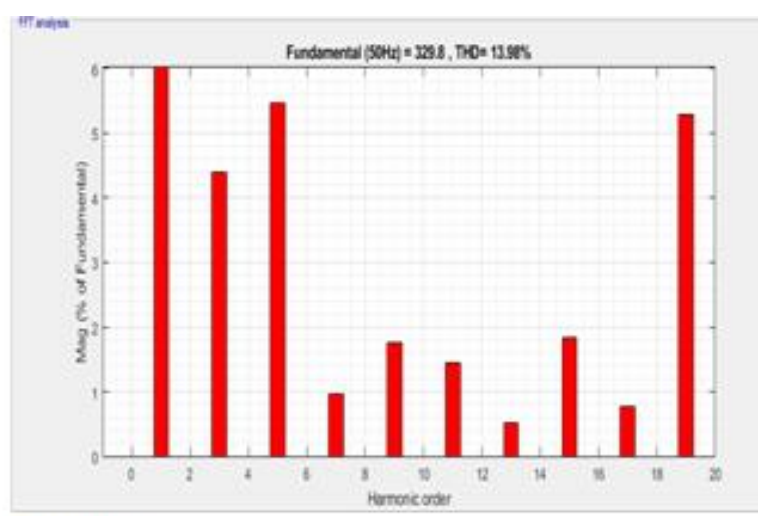

b) PSO Algorithm

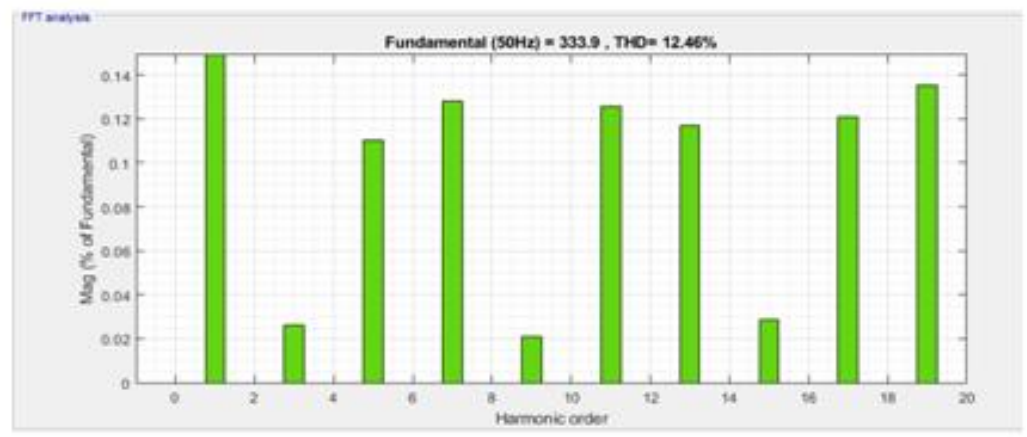

c) MVP Algorithm

Fig.5. FFT Analysis of 3 Phase Inverter

The quality of the output voltage waveform at the PCC is more important compared to the inverter voltage in the grid connected multilevel inverters. PCC plays a vital role to regulate the voltage profile and the harmonic control. The output voltage at PCC with the designed 9 -level CHBMLI using MVP algorithm is shown in figure 6. Table support the proposed MVP algorithm as it mitigates the lower harmonic with optimal switching angles and results improved quality of output wave from in comparison to the other two methods adopted.

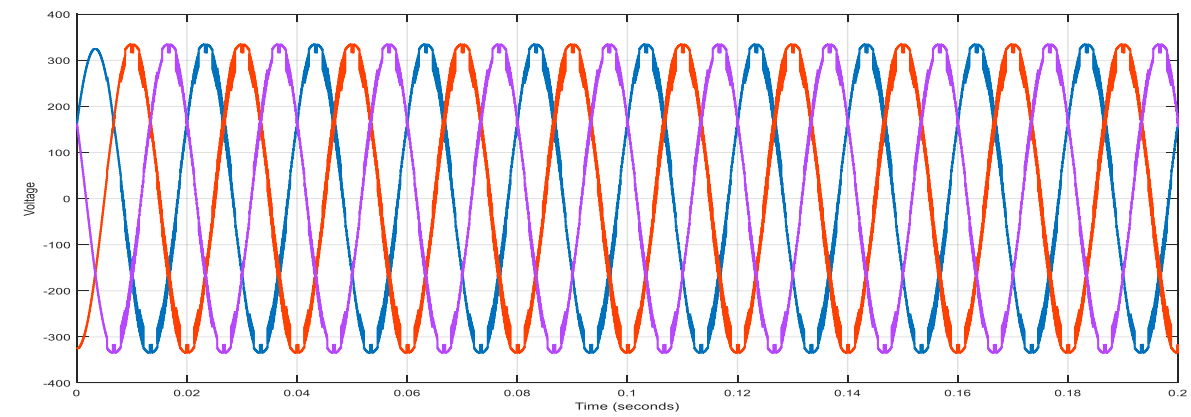

Fig. 6. Voltage at PCC with MVPA.

The fig. 7 demonstrates the harmonic spectrum at the PCC output voltage with NR Method, PSO algorithm and MVPA algorithm. 

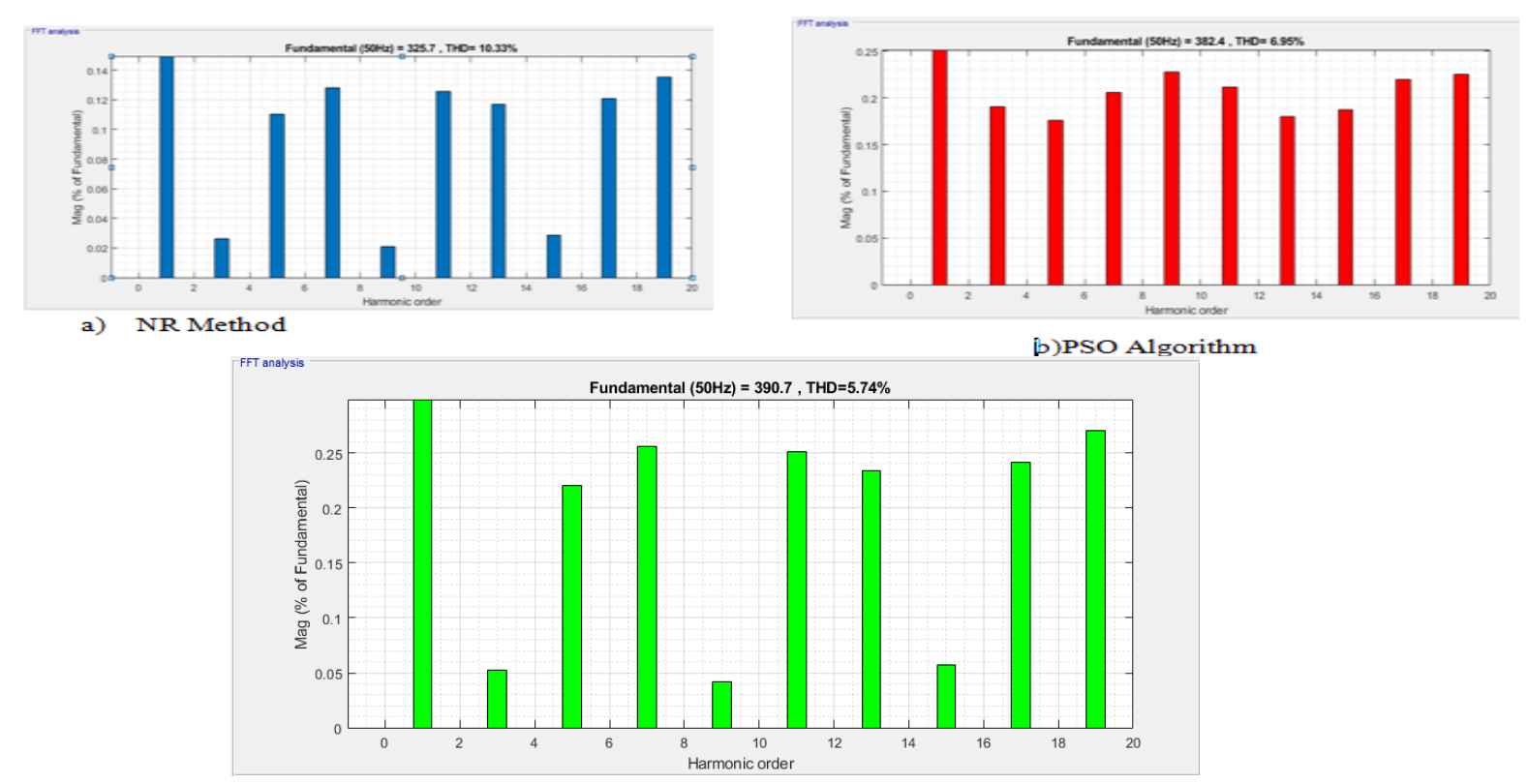

c) MVP Algorithm

Fig.7. FFT Analysis at PCC

\section{Conclusion}

In this paper a nine level CHBMLI is presented with an objective of improving voltage quality at PCC and reduced harmonic levels. The CHBMLI technique yields in a better output voltage with a modularized circuit and packing layout. CHBMLI also results in better control, low switching losses and less no of power semiconductor switches in comparison to other MLI techniques. The nine level CHBMLI is designed based on SHE with an aim of reducing, 5th, 7th and 11th harmonics at the output of inverter terminals. The firing angles for the nine level CHBMLI are derived using NR, PSO and MVPA algorithms. Simulation results shows that voltage magnitude obtained using MVPA algorithm results in a closed magnitude with PCC voltage. FFT analysis of NR, PSO and MVPA algorithms indicates that MVPA algorithm validates with a minimum THD in comparison with other method. Hence, the proposed MVPA algorithm results in an optimal solution with respect to harmonic distortion and accuracy.

Further the proposed CHBMLI can be extended with suppression of more harmonic levels. It can also be implemented to any number of levels with the different applications in near future.

\section{References}

1. Chiasson, J.N., Tolbert, L.M., McKenzie, K.J., et al.: "Elimination of harmonics in a multi level converter using theory of symmetric polynomials and resultants", IEEE Trans. Control syst. Technol., 13 (2),pp.216223,2005.

2. J. Rodríguez, J.-S. Lai, and F. Z. Peng, "Multilevel inverters: A survey of topologies, controls, and applications,” IEEE Trans. Ind. Electron., vol. 49, no. 4, pp. 724-738, Aug. 2002.

3. L. G. Franquelo, J. Rodriguez, J. I. Leon, S. Kouro, R. Portillo, and M. A. M. Prats, "The age of multilevel converters arrives," IEEE Trans. Ind. Electron. Mag., vol. 2, no. 2, pp. 28-39, June, 2008.

4. A. Nami. "A New Multilevel Converter Configuration for High-Power High-Quality Application," PhD Thesis, Queensland University of Technology, 2010.

5.Thiyagarajan V, Somasundaram P, "A New Seven Level Symmetrical Inverter with Reduced Switch Count," International Journal of Power Electronics and Drive System (IJPEDS), vol. 9, no. 2, pp. 921-925, Jun 2018.

6. I. López, S. Ceballos, J. Pou, J. Zaragoza, J. Andreu, I. Kortabarria and V. G. Agelidis, "Modulation strategy for multiphase Neutral-Point Clamped converters," IEEE Trans. Power Electron., vol. 31, no. 2, pp. 928941, March, 2015.

7. MotaparthiNagaraju, MalliguntaKiran Kumar, "Analysis of series/parallel multilevel inverter with symmetrical and asymmetrical configurations," International Journal of Power Electronics and Drive System (IJPEDS), vol. 10, no. 1, pp. 300-306, Mar 2019.

P. W. Hammond, "A new approach to enhance power quality for medium voltage AC drives," IEEE Trans. Ind. Appl., vol. 33, no. 1, pp. 202-208, Jan./Feb. 1997. 
8. Mariusz Malinowski, K. Gopakumar, Jose Rodriguez, Marcelo A. Pérez, “A Survey on Cascaded Multilevel Inverters”, IEEE Trans. Ind. Electron, vol. 57, no. 7,, pp. no. 2197-2206, 2010.

9. S Sabyasachi, et. al. "Hybrid control technique-based three-phase cascaded multilevel Inverter topology" IEEE Access, Vol 5, pp. 26912-26921, 2017.

10. Corzine KA, Wielebski MW, Peng FZ, Wang J. "Control of cascaded multi-level inverters". IEEE Trans Power Electron, Vol 19 No 3, pp 732-738,2004;

11. Milan Srndovic , et. al," Simultaneous Selective Harmonic Elimination and THD Minimization for a SinglePhase Multilevel Inverter With Staircase Modulation”, IEEE Transactions On Industry Applications, vol. 54, no. 2, pp 1532-1541,2018

12 .Patel HS, HoftRG., "Generalized techniques of harmonic elimination and voltage control in thyristor inverters: part I - Harmonic elimination”, IEEE Trans IndAppl, vol 3, no 3, pp 310-7,1973.

13. John N. Chiasson, Leon M. Tolbert, Keith J. McKenzie, Zhong Du, "A complete solution to the harmonic elimination problem", IEEE Trans. Pow. Electron, vol 19, no 2,

14. Memom, M.A., Mekhilef, s., Mubin, M., et al.: "Selective harmonic elimination in inverters using bioinspired intelligent algorithms for renewable energy conversion applications: a review", Renew. Sustain. Energy Rev., 82, pp.89-95, 2018

15. ChallapalliRoja, Dr.Dondapati Ravi kishore, "Grid Connected PV based Buck \& Boost converter for Mismatched Environmental Conditions using FUZZY \& PSO”, International Journal of Control and Automation vol. 13, no. 1s, pp. 01-10,2020

16. El-Naggar, k., Abdelhamid, T.H.: 'Selective harmonic elimination of new family of multi level inverters using genetic algorithms', Energy Convers. Manage., 1, (49), pp. 89-95,2008.

17. Ramkumar, Kamaraj, Thamizharasan, "GA Based Optimization and Critical Evaluation SHE Methods for Three-level Inverter", 2011 1st International Conference on Electrical Energy Systems

18. N. A Azli, Y. C. Choong," Analysis on the Performance of a Three-phase Cascaded H-Bridge Multilevel Inverter", First International Power and Energy CoferencePECon 2006 November 28-29, 2006, Putrajaya, Malaysia, pp. 405-410.

19. HemaLathaJavvaji, BasavarajaBanakara, "Simulation \& analysis of different parameters of various levels of cascaded $\mathrm{H}$ bridge multilevel inverter," IEEE Asia Pacific Conference on Postgraduate Research in Microelectronics and Electronics (Prime Asia), 2013; 62-67.

20.HemalathaJavvaji, BasavarajaBanakara, “An enhanced 17-level hybridized multilevel inverter with stair case modulation", International Journal of Power Electronics and Drive System (IJPEDS) Vol. 11, No. 4, December 2020, pp. 1872-1882.

21. Kennedy.J, Eberhart.R, Particle swarm optimization, in: IEEE Int. Conf. Neural Networksvol. 4. IEEE Press, 1995: pp. 1942-1948.

22. H. Bouchekara, "Most Valuable Player Algorithm: a novel optimization algorithm inspired from sport", Operational Research, vol 20,pp. 139-195,2017.. 